\title{
Ipilimumab in the treatment of metastatic melanoma: management of adverse events
}

This article was published in the following Dove Press journal:

OncoTargets and Therapy

19 February 2014

Number of times this article has been viewed

\section{Giuseppina Della Vittoria \\ Scarpati ${ }^{1,2}$ \\ Celeste Fusciello ${ }^{3}$ \\ Francesco Perri ${ }^{4}$ \\ Francesco Sabbatino ${ }^{5}$ \\ Soldano Ferrone ${ }^{5}$ \\ Chiara Carlomagno 3 \\ Stefano Pepe ${ }^{1,2}$}

'Department of Medicine, University of Salerno, ${ }^{2}$ Division of Oncology, "San Giovanni di Dio e Ruggi d’Aragona” Hospital, Salerno, ${ }^{3}$ Department of Clinical Medicine and Surgery, University Federico II, Naples, ${ }^{4} \mathrm{Head}$ and Neck Medical Oncology Unit, National Tumor Institute, Naples, Italy; ${ }^{5}$ Department of Surgery, Massachusetts General Hospital, Harvard Medical School, Boston, MA, USA
Correspondence: Giuseppina Della Vittoria Scarpati

AOU San Giovanni di Dio e Ruggi d'Aragona, Largo Città d'Ippocrate, Salerno, Italy

Email giuseppina.dellavittoria@alice.it
Abstract: Recently, “ipilimumab,” an anti-cytotoxic T-lymphocyte antigen-4 (CTLA-4) monoclonal antibody, has been demonstrated to improve overall survival in metastatic melanoma. "CTLA-4" is an immune-checkpoint molecule that downregulates pathways of T-cell activation. Ipilimumab, by targeting CTLA-4, is able to remove the CTLA-4 inhibitory signal, allowing the immune system to react to cancer cells. Due to its immune-based mechanism of action, ipilimumab causes the inhibition of CTLA-4-mediated immunomodulatory effects, the enhancement of antitumor specific immune response mediated by the weakening of self-tolerance mechanisms while exacerbating the development of autoimmune diseases and immune-related adverse events, including dermatitis, hepatitis, enterocolitis, hypophysitis, and uveitis.

Keywords: melanoma, T-cells, CTLA-4, autoimmunity, adverse events

\section{Introduction}

"Ipilimumab" is a recombinant human immunoglobulin (Ig) G1 monoclonal antibody targeting the "cytotoxic T-lymphocyte antigen" (CTLA-4), a negative regulator of T-cell activation, expressed by activated T-cells as well as by T-regulatory cells. ${ }^{1}$

Both T-cell receptors cluster of differentiation (CD) 28 and CTLA-4 react with two ligands displayed on the cell surface by antigen-presenting cells, CD80 and CD86. CD28 and CTLA-4 function antagonistically; in fact, the interaction between CD28 and either CD80 or CD86 enhances T-cell activation, proliferation, and interleukin-2 (IL-2) production. In contrast, CTLA-4, which binds to CD80 and CD86 with greater affinity than to CD28, antagonizes T-cell activation by interfering with IL-2 secretion and IL-2-receptor expression. Ipilimumab, by binding CTLA-4, is able to block its interaction with CD80 or CD86 and allows for optimal interaction between T-cell CD28 receptors and CD80/86, therefore resulting in optimal T-cell activation. ${ }^{1}$

Ipilimumab has demonstrated a significant benefit in improving overall survival (OS) in patients affected by metastatic melanoma in two Phase III trials, namely the MDX010-20 Phase III trial, ${ }^{2}$ which compared ipilimumab with a vaccine against glycoprotein 100, and the CA184-024 study, ${ }^{3}$ in which standard treatment (dacarbazine) was compared with dacarbazine plus ipilimumab. ${ }^{4}$ In the first study, ipilimumab demonstrated median OS of 10 months and patients that showed a long duration response or partial/complete response were subsequently treated with reinduction of ipilimumab when they had disease progression. In the second study, the addition of ipilimumab to dacarbazine significantly improved OS, with high OS rates at 1,2, and 3 years of follow-up. The results of these studies have been confirmed by data from an 
expanded access program. ${ }^{5}$ Further, ipilimumab has shown to achieve unusually long-term responses in individual patients and a relatively higher response rate (from $10 \%$ to $15 \%$ ) than that obtained with traditional drugs and/or B-raf inhibitors. ${ }^{6}$ For all these reasons, ipilimumab has been approved for the treatment of metastatic melanoma at a regimen of $3 \mathrm{mg} / \mathrm{kg}$ intravenously every 3 weeks for four doses by the US Food and Drug Administration in first-line treatment and by the European Medicine Agency in second- and following lines of treatment.

Lastly, new monoclonal antibodies targeting CTLA-4, such as tremelimumab (Pfizer, New York, NY, USA) and nivolumab (Bristol-Myers Squibb, New York, NY, USA), also known as "MDX1106," which block programmed cell death 1 (PD-1), have been developed for the treatment of metastatic melanoma. "PD-1" is a key immune-checkpoint receptor expressed by activated T-cells, similar to CTLA-4, that binds two different ligands: PD1-L1 and PD1-L2. This inhibits the cytokine production from and cytolytic activity of PD-1, and tumor cells can escape immune-system control and begin to grow without control. Monoclonal antibodies directed against PD-1 and PD1-L1 may be able to stimulate the cytotoxic activity of the immune system and to inhibit tumor growth. Published clinical trial results indicate that the toxicity profile of these drugs appears to be similar to that shown by ipilimumab. ${ }^{7}$

\section{Immune-related adverse events}

Treatment with the fully human anti-CTLA-4 monoclonal antibody ipilimumab is typically associated with the onset of immune-related adverse events (irAEs) which are strongly related to its immune-based mechanism of action. CTLA-4 blockade removes CTLA4-mediated protection from autoimmunity, and it is responsible for a large spectrum of autoimmune-inflammatory side effects, classified as irAEs. ${ }^{8-10}$ A retrospective analysis of several ipilimumab Phase I-III trials in patients with advanced melanoma showed that irAEs occurred in about $64.2 \%$ of treated patients and resulted in death in $<1 \%$ of them. ${ }^{11}$ The most common immune-mediated effects were enterocolitis, dermatitis, hepatitis, hypophysitis, and uveitis, which developed particularly during the induction phase. Time to resolution of irAEs varied from 4.3 to 7.7 weeks. ${ }^{12}$ However, recently, some evidence has indicated that ipilimumab-induced irAEs may be associated with clinical benefit, ${ }^{13,14}$ even in the adjuvant setting in resected high-risk stage IIIC/IV melanoma patients. ${ }^{15}$ Nevertheless, these data need to be verified by further clinical trials, since other studies have shown no correlation between toxicity and efficacy. ${ }^{2,16}$

The correct management of irAEs involves prompt medical attention and the early administration of high-dose systemic corticosteroids for grade 3 or 4 events. Bristol-Myers Squibb has developed specific guidelines to assist health-care professionals in the management of irAEs. Tables 1 and 2 describe the common side effects of ipilimumab and their management.

\section{Gastrointestinal toxicity}

Among all ipilimumab-induced irAEs, those affecting the gastrointestinal (GI) tract (GI irAEs) are the most frequent. GI irAEs may present through a wide spectrum of clinical manifestations (usually defined during clinical trials according to the National Cancer Institute's Common Terminology Criteria for Adverse Events v $3 \cdot 0^{17}$ ). Fever, weakness, abdominal pain, or an increase in the number of bowel movements, hematochezia, nausea, and vomiting have been reported. ${ }^{12}$ The most frequent GI side effect is diarrhea, characterized by watery/bloody stools, reported with a frequency of $20 \%-31 \%$ in the ipilimumab groups of the MDX010-20 Phase III trial, which led in 2011 to US Food and Drug Administration and European Medicines Agency approval of ipilimumab treatment at the dosage of $3 \mathrm{mg} / \mathrm{kg}$ for metastatic melanoma. In that trial, diarrhea and other GI side effects were reported to occur 5 to 12 weeks after the first drug administration. The use of a specific protocol for toxicity management often led to the resolution of these side effects in a median time of about 4 weeks from onset. ${ }^{18}$ The careful monitoring of signs and symptoms that suggest GI irAE onset is of the utmost importance; at the beginning of treatment, all patients as well as caregivers should be trained to refer any changes in clinical condition, especially in bowel habits, to physicians as early as possible in order to allow timely treatment and avoid more serious, life-threatening complications such as bowel perforation and obstruction. Rarely, diarrhea may hide bowel ulceration or perforation; in fact, immune-related colitis usually involves a descending colon and can present as a weak pain and diarrhea. ${ }^{19}$ Histopathologic findings of biopsies obtained after the onset of diarrhea often reveal features of diffuse active colitis with infiltrates of neutrophils, lymphocytes, and plasma cells in the lamina propria, together with crypt abscesses and mucosal ulcerations. ${ }^{20}$

In patients reporting low-grade GI toxicity (mild to moderate diarrhea or colitis), a symptomatic treatment consisting of loperamide, fluids, and electrolyte replacement, together with 
Table I Most common side effects of ipilimumab and their grades

\begin{tabular}{|c|c|c|c|c|}
\hline $\begin{array}{l}\text { Treatment- } \\
\text { related AE }\end{array}$ & Grade I & Grade 2 & Grade 3 & Grade 4 \\
\hline Skin toxicity & $\begin{array}{l}\text { Mild to moderate } \\
\text { localized rash or pruritus; } \\
\text { papules/pustules covering } \\
<10 \%-30 \% \text { of body } \\
\text { surface }\end{array}$ & $\begin{array}{l}\text { Nonlocalized rash } \\
\text { (diffuse, } \leq 50 \% \text { of skin surface) }\end{array}$ & $\begin{array}{l}\text { Intense or widespread rash }>30 \% \text {; } \\
\text { skin sloughing }<10 \%-30 \% \\
\text { of body surface; epidermal } \\
\text { or mucus membrane detachment }\end{array}$ & $\begin{array}{l}\text { Stevens-Johnson syndrome, } \\
\text { toxic epidermal necrolysis, } \\
\text { or rash complicated by full- } \\
\text { thickness dermal ulceration, } \\
\text { or necrotic, bullous, or } \\
\text { hemorrhagic manifestations }\end{array}$ \\
\hline Diarrhea & $\begin{array}{l}\text { Increase of }<4 \text { stools } \\
\text { per day over baseline; } \\
\text { mild increase in ostomy } \\
\text { output compared with } \\
\text { baseline }\end{array}$ & $\begin{array}{l}\text { Increase of } 4-6 \text { stools per day } \\
\text { over baseline; IV fluids indicated } \\
<24 \text { hours; moderate increase } \\
\text { in ostomy output compared to } \\
\text { baseline; not interfering with ADL }\end{array}$ & $\begin{array}{l}\text { Increase of } \geq 7 \text { stools per day over } \\
\text { baseline; incontinence; IV fluids } \\
\geq 24 \text { hours; hospitalization; severe } \\
\text { increase in ostomy output compared } \\
\text { with baseline; interfering with ADL }\end{array}$ & $\begin{array}{l}\text { Life-threatening consequences } \\
\text { (eg, hemodynamic collapse) }\end{array}$ \\
\hline Liver toxicity & $\begin{array}{l}\text { Asymptomatic or mild } \\
\text { symptoms; clinical or } \\
\text { diagnostic observations } \\
\text { only; intervention } \\
\text { not indicated }\end{array}$ & $\begin{array}{l}\text { AST or ALT }>2.5 \text { to } \leq 5.0 \times \text { ULN } \\
\text { and/or total bilirubin }>1.5 \\
\text { to } \leq 3.0 \times \text { ULN }\end{array}$ & $\begin{array}{l}\text { AST or ALT }>5 \times \text { ULN and/or } \\
\text { total bilirubin }>3.0 \times \text { ULN }\end{array}$ & $\begin{array}{l}\text { Moderate to severe } \\
\text { encephalopathy with abnormal } \\
\text { plasma levels of ammonia, } \\
\text { bilirubin, lactic dehydrogenase, } \\
\text { and alkaline phosphatase }\end{array}$ \\
\hline $\begin{array}{l}\text { Endocrine } \\
\text { toxicity }\end{array}$ & $\begin{array}{l}\text { Asymptomatic; } \\
\text { clinical or diagnostic } \\
\text { observations only; } \\
\text { intervention not indicated }\end{array}$ & $\begin{array}{l}\text { Moderate symptoms; } \\
\text { medical intervention } \\
\text { indicated }\end{array}$ & $\begin{array}{l}\text { Severe symptoms; } \\
\text { hospitalization indicated }\end{array}$ & $\begin{array}{l}\text { Adrenal crisis: severe } \\
\text { dehydration, hypotension, } \\
\text { or shock. Life-threatening } \\
\text { consequences }\end{array}$ \\
\hline
\end{tabular}

Abbreviations: AE, adverse event; ADL, activities of daily living; ALT, alanine transaminase; AST, aspartate aminotransferase; IV, intravenous; ULN, upper limits of normal.

Table 2 Management of ipilimumab-related side effects

\begin{tabular}{|c|c|c|c|c|}
\hline Side effect & Grade I & Grade 2 & Grade 3 & Grade 4 \\
\hline $\begin{array}{l}\text { Skin } \\
\text { toxicity }\end{array}$ & $\begin{array}{l}\text { Antihistamines and topical } \\
\text { corticosteroids; if no } \\
\text { response, consider oral } \\
\text { corticosteroids }\end{array}$ & $\begin{array}{l}\text { Antihistamines and topical } \\
\text { corticosteroids if no response, } \\
\text { consider oral corticosteroids }\end{array}$ & $\begin{array}{l}\text { High-dose systemic } \\
\text { corticosteroid therapy }\end{array}$ & $\begin{array}{l}\text { High-dose systemic } \\
\text { corticosteroid therapy; } \\
\text { antibiotics if indicated and } \\
\text { definitive discontinuation } \\
\text { of ipilimumab }\end{array}$ \\
\hline Diarrhea & $\begin{array}{l}\text { Anti-diarrhea drugs, } \\
\text { loperamide and } \\
\text { diphenoxylate } \\
\text { Patient hydration }\end{array}$ & $\begin{array}{l}\text { Anti-diarrhea drugs } \\
\text { Loperamide and diphenoxylate } \\
\text { Patient hydration }\end{array}$ & $\begin{array}{l}\text { Hospitalization, patients } \\
\text { hydration and systemic } \\
\text { corticosteroids }\end{array}$ & $\begin{array}{l}\text { Hospitalization, patient } \\
\text { hydration, and systemic } \\
\text { corticosteroids } \\
\text { Definitive discontinuation } \\
\text { of ipilimumab }\end{array}$ \\
\hline $\begin{array}{l}\text { Liver } \\
\text { toxicity }\end{array}$ & Monitoring of LFTs & $\begin{array}{l}\text { Withhold ipilimumab dose and check } \\
\text { LFTs every day for } 3 \text { consecutive } \\
\text { days; if LFT improvement to grade I, } \\
\text { resume routine monitoring } \\
\text { of LFTs and continue ipilimumab } \\
\text { If no improvement in the LFTs, } \\
\text { administer corticosteroid } \\
\text { treatment and skip the next } \\
\text { ipilimumab dose until event } \\
\text { resolves }\end{array}$ & $\begin{array}{l}\text { Withhold ipilimumab dose } \\
\text { and check LFTs every day } \\
\text { for } 3 \text { consecutive days; if LFT } \\
\text { improvement to grade I, } \\
\text { resume routine monitoring of } \\
\text { LFTs and continue ipilimumab } \\
\text { If no improvement in LFTs, } \\
\text { administer corticosteroid } \\
\text { treatment and skip the next dose } \\
\text { of ipilimumab until event resolves }\end{array}$ & $\begin{array}{l}\text { High dose of intravenous } \\
\text { corticosteroids } \\
\text { Definitive discontinuation } \\
\text { of ipilimumab }\end{array}$ \\
\hline $\begin{array}{l}\text { Endocrine } \\
\text { toxicity }\end{array}$ & $\begin{array}{l}\text { Abnormal endocrine workup, } \\
\text { grade I or } 2 \text { endocrine } \\
\text { toxicity without adrenal crisis } \\
\text { may resolve spontaneously } \\
\text { If no spontaneous resolution, } \\
\text { consider low-moderate dose } \\
\text { of systemic corticosteroids } \\
\text { Consider temporary } \\
\text { ipilimumab suspension }\end{array}$ & $\begin{array}{l}\text { Patients with symptoms suggestive } \\
\text { of hypophysitis require prompt } \\
\text { corticosteroid therapy } \\
\text { Temporary ipilimumab suspension }\end{array}$ & $\begin{array}{l}\text { Intravenous corticosteroids } \\
\text { Hormone replacement } \\
\text { Hydration } \\
\text { Electrolyte replacement } \\
\text { Temporary ipilimumab } \\
\text { suspension }\end{array}$ & $\begin{array}{l}\text { Intravenous } \\
\text { corticosteroids } \\
\text { Hormone replacement } \\
\text { Hydration } \\
\text { Electrolyte replacement } \\
\text { Definitive discontinuation } \\
\text { of ipilimumab }\end{array}$ \\
\hline
\end{tabular}

Abbreviation: LFT, liver function tests. 
the close monitoring of signs and symptoms, is recommended. The next scheduled dose of ipilimumab should be omitted until resolution of the symptoms or the achievement of grade 1 toxicity. ${ }^{21}$ In the case of rectal bleeding, persistent grade 2 toxicity or higher diarrhea, a complete laboratory/endoscopic workup should be performed in order to rule out other causes of colitis, such as infection or inflammatory bowel disease; corticosteroid administration should be considered and some researchers even propose treatment with oral diphenoxylate hydrochloride, atropine sulfate, and budesonide $9 \mathrm{mg}$ once per day. ${ }^{22}$ When severe diarrhea or colitis occurs (grade 3-4), treatment with ipilimumab must be permanently discontinued, and appropriate therapy with high-dose intravenous steroids (methylprednisolone $2 \mathrm{mg} / \mathrm{kg} /$ day) started immediately, together with adequate fluid/electrolyte replacement. Maintenance oral prednisolone (1-2 mg/kg/day) may be employed. Once improvement of symptoms and clinical condition is achieved, a slow tapering of corticosteroids can be initiated according to the clinician's judgment; it is noteworthy to underline the extreme importance of performing a gradual weaning from steroids, over a period of at least 1 month, in order to avoid early recurrence. ${ }^{12}$

Prophylactic use of budesonide $9 \mathrm{mg}$ /day during treatment with ipilimumab has been tested in a Phase II trial performed by Wolchok et al. ${ }^{19}$ However, the drug was not recommended since it did not demonstrate efficacy in preventing the onset of GI toxicity. In rare cases of steroid-resistant GI irAEs, treatment with a single dose of the immunosuppressive agent infliximab at $5 \mathrm{mg} / \mathrm{kg}$ in addition to corticosteroids can be considered unless the sepsis or GI perforation is suspected; to avoid early recurrence, steroid administration should be tapered over $45-60$ days. ${ }^{22}$

\section{Immune-related hepatotoxicity}

Hepatic irAEs were reported with a low frequency (about 3\%) in patients treated with ipilimumab in the MDX010-20 clinical trial, with an average time to onset of 3 to 9 weeks for serious events and a time to resolution - with prompt treatment according to specific guideline recommendations - of about 2 weeks.

Usually, ipilimumab-induced hepatitis is characterized by an asymptomatic worsening of liver function tests (LFTs), such as an elevation of alanine transaminase (ALT)/aspartate aminotransferase (AST) or bilirubin levels, although fatigue and fever also occur. ${ }^{7}$ A complete workup to rule out viral hepatitis, disease progression (liver metastases), or other drug-related toxicity must be performed. Liver biopsies have been reported to show the hallmarks of both "acute" hepatitis, with necrosis and perivenular infiltrate (damage of hepatocytes) and "biliary" hepatitis (predominant damage of bile ducts); imaging findings in cases of serious liver damage revealed the presence of hepatomegaly, periportal edema and diffuse low-attenuation liver parenchyma. ${ }^{23}$

Because of the typical asymptomatic onset of immunerelated hepatitis, LFTs must be assessed before each ipilimumab administration and carefully monitored subsequently.

If AST/ALT levels present in the range of $>5$ to $<8 \times$ above the upper limits of normal levels (ULN) or total bilirubin is in the a range of $>3$ to $<5 \times$ above ULN, the next dose of ipilimumab should be omitted and LFTs should be monitored until resolution of the toxicity; once AST/ALT levels return to $<5 \times$ over ULN and total bilirubin $<3 \times$ over ULN, treatment with ipilimumab can be restarted with the next scheduled dose. ${ }^{21}$ In the case of AST/ALT levels, elevation of $>8 \times$ over ULN means that ipilimumab treatment must be permanently discontinued and intravenous highdose corticosteroid treatment must be immediately started (methylprednisolone $2 \mathrm{mg} / \mathrm{kg} /$ day or equivalent) for 24-48 hours, followed by oral prednisone $1-2 \mathrm{mg} / \mathrm{kg} / \mathrm{day}$; LFTs must be monitored daily until AST/ALT levels begin to drop. Once LFT improvement is achieved, a slow steroid tapering could be considered, according to clinical judgment, over a period of at least 30 days in order to avoid recurrence. ${ }^{22}$ Ipilimumab-induced hepatitis is usually highly responsive to adequate steroid administration, but some cases of refractory hepatotoxicity have been reported. If serum transaminase levels do not decrease within about 48 hours after starting steroids, the administration of oral mycophenolate mofetil could be considered; infliximab should be avoided in these patients because of its hepatotoxicity. ${ }^{24}$ Interestingly, Chmiel at al reported a case of a severe ipilimumab-induced hepatitis refractory to steroids and mycophenolate mofetil, which was resolved with the administration of antithymocyte globulin. ${ }^{25}$

\section{Skin toxicity}

Dermatologic toxicity (DT) is the most common ipilimumabinduced irAE, but it is rarely of severe grade, being classified in the majority of the cases as grade 1-2. DT generally appears after 2-4 weeks of treatment. ${ }^{21,24}$ Patients should be advised to report any skin changes and to monitor for rash and pruritus appearance. ${ }^{19}$ Maculopapular rashes occur in $10 \%-50 \%$ of patients treated with ipilimumab, with or without pruritus. ${ }^{26}$ For patients with nonlocalized rash or diffuse rash over less than $50 \%$ of the skin, ipilimumab can be withheld and topical or systemic corticosteroids such as betamethasone 
$0.1 \%$, hydrocortisone $1 \%$, or urea-based topical therapies with antipruritic agents can be dispensed. ${ }^{1}$ Sun avoidance and the use of broad-spectrum sunscreen is recommended prophylactically. The use of oral antihistamines may also assist with pruritus. ${ }^{27}$ Ipilimumab should be interrupted for grade 3 dermatitis until the rash returns to grade 1-2, while grade 4 toxicity requires hospitalization. 22 "Stevens-Johnson syndrome," defined as rash complicated by dermal ulceration, necrotic, bullous or hemorrhagic manifestations, and toxic epidermal necrolysis, has sometimes been observed. ${ }^{22}$ In this case, ipilimumab should be permanently discontinued and systemic corticosteroids must be administered at $1-2 \mathrm{mg} / \mathrm{kg} /$ day of prednisone equivalent. ${ }^{21}$ Other reported skin reactions include prurigo, acneiform rash, lichenoid exanthema, pyoderma gangrenosum-like ulcerations, skin toxicity in the irradiated area, photosensitivity, and a drug rash with eosinophilia and systemic symptoms. ${ }^{26}$ Interestingly, melanoma-associated hypopigmentation has been reported and postulated to be prognostically favorable. ${ }^{26}$

\section{Endocrine AEs}

Although uncommon, "endocrinopathies" are a group of toxicities induced by ipilimumab and may include hypopituitarism, hypophysitis, hypothyroidism, and adrenal insufficiency. ${ }^{27}$ In the MDX010-20 trial, endocrine irAEs occurred in 4\%-8\% of all patients treated with ipilimumab. "Hypophysitis" is a rare, yet serious complication of ipilimumab treatment, with an incidence of up to $17 \% .{ }^{28}$ Symptoms include loss of libido, fatigue, headache, memory difficulties, dizziness, vision changes, and constipation. Symptoms of hypophysitis usually develop after 6 weeks of treatment and, when suspected, a complete workup, including serum potassium, sodium, morning cortisol, luteinizing hormone, follicle-stimulating hormone, testosterone, insulin-like growth factor-1 and free thyroxine dosage, as well as brain magnetic resonance imaging to exclude brain metastases, is mandatory. ${ }^{26} \mathrm{~A}$ report on nine patients treated with ipilimumab who developed autoimmune hypophysitis showed that eight of them had a correlative increase in pituitary size on imaging. Ipilimumab should be stopped in patients with evidence of autoimmune hypophysitis and be administered physiological hormone replacements, with hydrocortisone, thyroxine, and sexual hormones. A short course of high-dose steroids (prednisone at dose of $1-2 \mathrm{mg} / \mathrm{kg} /$ day) may improve pituitary function. If suspicion of an adrenal crisis subsists, an endocrinologist should be consulted and a stress dose of intravenous steroids such as dexamethasone 4 mg every 6 hours should be administered; a gonadal and thyroid hormone replacement, if required, should be performed. ${ }^{27}$ Longer-term management may involve tapering of steroids over a minimum of 4 weeks; however, many patients will require steroid replacement for longer periods. Ipilimumab may be re-instituted after resolution of grade 1-2 endocrinopathies, but, since the risk of further complications is unknown, its restart is not recommended in more severe cases. Recently, however, patients with hypophysitis needing hormone replacement have been retreated with ipilimumab without worsening side effects. ${ }^{27}$

\section{Other immune-related AEs}

Ophthalmological side effects are very rare and have been reported in less than $1 \%$ of treated patients. These events usually resolve within a week, but treatment with steroid eye drops may be required, and systemic corticosteroids in the more severe cases, such as uveitis, iritis, or episcleritis, are strongly recommended. ${ }^{27}$

Neurological toxicity such as Guillain-Barré syndrome, sensory or motor neuropathy, and myasthenia gravis have been reported in less than $1 \%$ of patients. Treatment with corticosteroids (prednisone 1-2 mg/kg/day) over 4 weeks in concomitance with cessation of ipilimumab is indicated for grade 3-4 neuropathy, while lower-grade neuropathy can be managed by holding the next dose of ipilimumab. Severe to fatal immune-related neuropathies have been rarely reported, and they were observed in less than $2 \%$ of patients receiving ipilimumab in the MDX010-20 study. ${ }^{12}$

Respiratory tract irAEs, such as alveolitis, atypical pneumonia, fatal acute respiratory distress syndrome, pulmonary granulomatosis, sarcoidosis, ${ }^{29-31}$ and adverse reactions affecting the renal tract have very rarely been observed; when they do occur, they have significant, often life-threatening, clinical implications. Sometimes the radiological signs of sarcoidosis can be confused with pulmonary metastases resulting in an inadequate change of therapy. Both conditions must be treated with high-dose steroids. ${ }^{31}$

\section{Conclusion}

The evidence that ipilimumab significantly improves OS in advanced melanoma patients has led to its approval for the treatment of pretreated metastatic melanoma. Ipilimumab, which inhibits CTLA-4, activates and prolongs the immune response, but this effect is associated with a high incidence of autoimmune pathologies, which are commonly manageable with steroids and other supportive cares. However, the efficacy of ipilimumab in controlling the disease, as documented in a number of clinical trials, should be taken into account and its suspension strongly discouraged. The 
adequate management of the immune-related side effects should be addressed by a multidisciplinary team with the aim of avoiding suspension or under dosage of the drug.

\section{Disclosure}

The authors declare no conflicts of interest in this work.

\section{References}

1. Patel SP, Woodman SE. Profile of ipilimumab and its role in the treatment of metastatic melanoma. Drug Des Devel Ther. 2011;5:489-495.

2. Bristol-Myers Squibb. MDX-010 Antibody, MDX-1379 Melanoma Vaccine, or MDX-010/MDX-1379 Combination Treatment for Patients With Unresectable or Metastatic Melanoma. Available from: http:// clinicaltrials.gov/show/NCT00094653. NLM identifier: NCT00094653. Accessed January 22, 2014.

3. Bristol-Myers Squibb. Dacarbazine and Ipilimumab vs. Dacarbazine With Placebo in Untreated Unresectable Stage III or IV Melanoma. Available from: http://clinicaltrials.gov/show/NCT00324155. NLM identifier: NCT00324155. Accessed January 22, 2014.

4. Hodi FS, O'Day SJ, McDermott DF, et al. Improved survival with ipilimumab in patients with metastatic melanoma. $N$ Engl J Med. 2010;363:711-723.

5. Di Giacomo AM, Danielli R, Calabrò L, et al. Ipilimumab experience in heavily pretreated patients with melanoma in an expanded access program at the University Hospital of Siena (Italy). Cancer Immunol Immunother. 2011;60(4):467-477.

6. Tarhini A. Immune-mediated adverse events associated with ipilimumab ctla-4 blockade therapy: the underlying mechanisms and clinical management. Scientifica (Cairo). 2013;2013:857519.

7. Ribas A, Chesney JA, Gordon MS, et al. Safety profile and pharmacokinetic analyses of the anti-CTLA4 antibody tremelimumab administered as a one hour infusion. J Transl Med. 2012;10:236.

8. Boasberg P, Hamid O, O'Day S. Ipilimumab: unleashing the power of the immune system through CTLA-4 blockade. Semin Oncol. 2010;37(5):440-449.

9. Di Giacomo AM, Biagioli M, Maio M. The emerging toxicity profiles of anti-CTLA-4 antibodies across clinical indications. Semin Oncol. 2010;37(5):499-507.

10. Phan GQ, Yang JC, Sherry RM, et al. Cancer regression and autoimmunity induced by cytotoxic $\mathrm{T}$ lymphocyte-associated antigen 4 blockade in patients with metastatic melanoma. Proc Natl Acad Sci US A. 2003;100(14):8372-8377.

11. Ibrahim R, Berman D, DePril V, et al. Ipilimumab safety profile: summary of findings from completed trials in advanced melanoma. J Clin Oncol. 2011;29(Suppl):Abstract 8583.

12. Andrews S, Holden R. Characteristics and management of immunerelated adverse effects associated with ipilimumab, a new immunotherapy for metastatic melanoma. Cancer Manag Res. 2012;4:299-307.

13. Lutzky J, Wolchok J, Hamid O, et al. Association between immune-related adverse events (irAEs) and disease control or overall survival in patients (pts) with advanced melanoma treated with $10 \mathrm{mg} / \mathrm{kg}$ ipilimumab in three phase II clinical trials. J Clin Oncol. 2009;27(15S):Abstract 9034.

14. Attia P, Phan GQ, Maker AV, et al. Autoimmunity correlates with tumor regression in patients with metastatic melanoma treated with anti-cytotoxic T-lymphocyte antigen-4. J Clin Oncol. 2005;23(25): 6043-6053.
15. Sarnaik AA, Yu B, Yu D, et al. Extended dose ipilimumab with a peptide vaccine: immune correlates associated with clinical benefit in patients with resected high-risk stage IIIc/IV melanoma. Clin Cancer Res. 2011;17(4):896-906.

16. Di Giacomo AM, Grimaldi AM, Ascierto PA, et al. Correlation between efficacy and toxicity in pts with pretreated advanced melanoma treated within the Italian cohort of the ipilimumab expanded access programme (EAP). J Clin Oncol. 2013;31(Suppl 15):Abstract 9065.

17. McDermott D, Haanen J, Chen TT, Lorigan P, O'Day S; MDX010-20 Investigators. Efficacy and safety of ipilimumab in metastatic melanoma patients surviving more than 2 years following treatment in a phase III trial (MDX010-20). Ann Oncol. 2013;24(10):2694-2698.

18. National Cancer Institute (NCI). Common Terminology Criteria for Adverse Events v 3.0. Bethesda, MD: NCI; 2006. Available from: http:// ctep.cancer.gov/protocolDevelopment/electronic_applications/docs/ ctcaev3.pdf. Accessed December 30, 2013.

19. Wolchok JD, Neyns B, Linette G, et al. Ipilimumab monotherapy in patients with pretreated advanced melanoma: a randomised, double-blind, multicentre, phase 2, dose-ranging study. Lancet Oncol. 2010;11(2):155-164.

20. Berman D, Parker SM, Siegel J, et al. Blockade of cytotoxic T-lymphocyte antigen-4 by ipilimumab results in dysregulation of gastrointestinal immunity in patients with advanced melanoma. Cancer Immun. 2010;24;10:11.

21. Yervoy (ipilimumab): Immune-mediated adverse reaction management guide. Available from: http://www.yervoy.com/hcp/pdf/rems-managementguide.pdf. Accessed Oct 2011.

22. Weber JS, Kähler KC, Hauschild A. Management of immune-related adverse events and kinetics of response with ipilimumab. J Clin Oncol. 2012;30(21):2691-2697.

23. Kim KW, Ramaiya NH, Krajewski KM, et al. Ipilimumab associated hepatitis: imaging and clinicopathologic findings. Invest New Drugs. 2013;31(4):1071-1077.

24. Kähler KC, Hauschild A. Treatment and side effect management of CTLA-4 antibody therapy in metastatic melanoma. J Dtsch Dermatol Ges. 2011;9(4):277-286. English and German.

25. Chmiel KD, Suan D, Liddle C, et al. Resolution of severe ipilimumabinduced hepatitis after antithymocyte globulin therapy. J Clin Oncol. 2011;29(9):e237-e240.

26. Voskens CJ, Goldinger SM, Loquai C, et al. The price of tumor control: an analysis of rare side effects of anti-CTLA-4 therapy in metastatic melanoma from the ipilimumab network. PLoS One. 2013;8(1): e53745.

27. Lemech C, Arkenau HT. Novel treatments for metastatic cutaneous melanoma and the management of emergent toxicities. Clin Med Insights Oncol. 2012;6:53-66.

28. Dillard T, Yedinak CG, Alumkal J, et al. Anti-CTLA-4 antibody therapy associated autoimmune hypophysitis: serious immune related adverse events across a spectrum of cancer subtypes. Pituitary. 2010;13(1):29-38.

29. Berthod G, Lazor R, Letovanec I, et al. Pulmonary sarcoid-like granulomatosis induced by ipilimumab. J Clin Oncol. 2012;30: e156-e159.

30. Eckert A, Schoeffler A, Dalle S, Phan A, Kiakouama L, Thomas L. Anti-CTLA4 monoclonal antibody induced sarcoidosis in a metastatic melanoma patient. Dermatology. 2009;218(1):69-70.

31. Heinzerling LM, Anliker MD, Müller J, Schlaeppi M, von Moos R. Sarcoidosis induced by interferon- $\alpha$ in melanoma patients: incidence, clinical manifestations, and management strategies. J Immunother. 2010;33(8):834-839. 
OncoTargets and Therapy

\section{Publish your work in this journal}

OncoTargets and Therapy is an international, peer-reviewed, open access journal focusing on the pathological basis of all cancers, potential targets for therapy and treatment protocols employed to improve the management of cancer patients. The journal also focuses on the impact of management programs and new therapeutic agents and protocols on
Dovepress

patient perspectives such as quality of life, adherence and satisfaction. The manuscript management system is completely online and includes a very quick and fair peer-review system, which is all easy to use. Visit http://www.dovepress.com/testimonials.php to read real quotes from published authors.

\footnotetext{
Submit your manuscript here: http://www.dovepress.com/oncotargets-and-therapy-journal
} 